\title{
Determination of Iron Content of Three Common Acacias of Sudan
}

\author{
Isam Eldin Hussein Elgailani*, Christina Yacoub Ishak \\ Department of Chemistry, Faculty of Science, University of Khartoum, Khartoum, Sudan \\ Email: "gailani23@hotmail.com
}

Received 19 September 2015; accepted 13 November 2015; published 16 November 2015

Copyright (C) 2015 by authors and Scientific Research Publishing Inc.

This work is licensed under the Creative Commons Attribution International License (CC BY). http://creativecommons.org/licenses/by/4.0/

c) (i) Open Access

\section{Abstract}

The amount iron content of the extracts and samples of Acacia species was determined. Since the iron hinders the process of retanning leather, iron content is determined by wet digestion method and atomic absorption spectrophotometry. The iron contents of bark extract of Acacia nilotica, Acacia senegal and Acacia seyal were $0.0044 \%, 0.0040 \%$ and $0.0029 \%$ respectively. In contrast, the iron content of bark extract of the three species of Acacia had lower percentage compared to that of Mimosa (Acacia mearnsii) $(0.0047 \%)$, which was imported from Kenya. The iron content presented in leaves, barks, mature and immature fruits of Acacia species were determined by the same analytical methods. Bark and mature fruits of Acacia nilotica had the highest and equal percentage $(0.1450 \%)$. The percentage of iron content of leaves and bark of Acacia seyal had equal percentage $(0.0750 \%)$, while the bark of Acacia senegal had much lower percentage $(0.0375 \%)$.

\section{Keywords}

Acacia Species, Sudan, Iron Content, AAS

\section{Introduction}

The excess of Fe ions which was not absorbed appeared as spots of rust which was undesirable in the leather industry. The rusting of iron is the formation of hydrated oxide in the presence of oxygen and water. The rust formed on atmospheric exposure is usually more adherent than the produced by immersion. The alkali and ferrous salt, where they meet they will interact to give precipitate of yellow brown-rust consisting of hydrated ferric oxide $\mathrm{Fe}_{2} \mathrm{O}_{3} \cdot \mathrm{H}_{2} \mathrm{O}$, provided that plenty of oxygen was present. All these facts have been established by direct observation. The alkali and ferrous salt can be detected by simple test, the precipitation and settlement of the rust are obvious to the eye.

${ }^{*}$ Corresponding author. 
The main body of the rust is precipitated well, is composition and appearance depends on the oxygen supply. If oxygen is plentiful, $\mathrm{Fe}^{2+}, \mathrm{OH}^{-}$and $\mathrm{O}_{2}$ may interact to give hydrated ferric oxide as the first solid phase; but it is generally assumed that ferrous hydroxide or basic ferrous salt is first precipitated and then becomes oxidized. Such oxidize has been studied. With deficiency of oxygen, green ferroso-ferric compounds may appear, these appear to be not simply hydroxides, but to contain $\mathrm{Cl}^{-}$or $\mathrm{SO}_{4}^{2-}$. In some geometric situations, black magnetite is formed. The atmospheric corrosion set up in industrial or urban atmospheres containing sulphur dioxide (arising from the combustion of coal or oil containing sulphur) presents some different features. It would seem that sulphur oxide is needed to start rapid atmospheric rusting, but serves only as the source of ferrous sulphate, when ferrous sulphate has been formed, sulphur dioxide is no longer needed [1]. There is confusion in the literature regarding the composition of the material produced by the oxidation of ferrous hydroxide. The nature of the product is important, not only from the academic point of view, but also in connection with the theory of the mechanism of the inhibition of the correction of iron by alkaline solutions. The following investigation was carried out in order to clarify the position.

It is well Known that ferrous hydroxide is a white solid, which becomes green in the presence of a trace of air, if oxidation continues, the green material becomes known and may darken. Deiss and Schikorr (1928) examined the reaction and concluded that the green product was a basic ferrous ferrite, $\mathrm{Fe}(\mathrm{OH}) \cdot \mathrm{O} \cdot \mathrm{Fe}(\mathrm{OH})_{2}$. On the other hand, Girard and Chaudron (1935) regarded the green material as hydrated magnetite [2]. Green-blue hydroxide compounds occur under reducing and weakly alkaline conditions as intermediate phases in the formation of Fe oxides (goethite, lepidocrocite and magnetite). Because these green compounds were first discovered in conjunction with corrosion of steel in earth surface environments, there were called green rusts [3]. Metallic materials in practical use are normally exposed to corrosion in the atmospheric and aqueous environments. Corrosion is one of the problems we have often encountered in our industrialized society; hence it has been studied comprehensively since the industrial revolution in the late eighteen century [4]. Green rust are very reactive iron(II)iron(III) hydroxy-compounds were $\mathrm{Fe}(\mathrm{OH})_{2}$-like sheets alternate with interlayers composed of anions and water molecules. Various types of anions can lead to the formation of a green rust, e.g. $\mathrm{CO}_{3}^{2-}, \mathrm{Cl}^{-}$or $\mathrm{SO}_{4}^{2-}$ [5]. The oxidation of either pyrogallol- or catechol-tanned leather is accelerated greatly by iron. Vegetable-tanned leather was equally damaged by either ferrous sulphate or sulphuric acid solutions having $\mathrm{pH}$ values approximately 3.5 [6]. Micro-XRF maps show that $\mathrm{Cr}$ and $\mathrm{Fe}$ are distributed together in regions where their concentrations are diffuse, and at local spots where their concentrations are high. Iron oxides, which can reduce $\operatorname{Cr}(\mathrm{VI})$ to $\operatorname{Cr}(\mathrm{III})$, are present at some of these hot spots where $\mathrm{Cr}$ and Fe are highly concentrated [7].

In this work, we initiated this study in order to determine the content of iron in Acacia species that grow in Sudan, and to determine the amount of iron present and the distribution of this metal in different parts of the plants involved. Three common species, Acacia nilotica, Acacia seyal, and Acacia senegal, were selected for study. The amount of iron was determined by atomic absorption spectrometer (Perkin-Elmer, model 2380 AAS).

\section{Materials and Methods}

\subsection{Study Area and Sampling}

The samples Acacia nilotica and Acacia seyal were brought from Sunt Forest at Khartoum State, whereas the Acacia senegal samples were brought from Debeybat Forest at South Kordofan State in Sudan. Mimosa (Acacia mearnsii) extract were imported from Kenya by Khartoum Tannery. The samples used for the determination of iron content were mature and immature fruits, bark and leaves of Acacia nilotica. For Acacia seyal sample, the part analyzed were leaves and bark, while for Acacia senegal only bark was analyzed.

\subsection{Materials and Chemicals}

Materials and chemical used for the analysis in this work were of high grade.

\subsection{Extraction of Bark Samples}

The dried bark samples of the three Acacia species were ground in a mill. $40 \mathrm{~g}$ of each sample were extracted with deionized water, another with $80 \%$ methanol, and a third with $70 \%$ acetone (200 ml) by boiling for $10 \mathrm{mi}-$ nutes. The samples were filtered (Whatman 1 paper, $18.5 \mathrm{~cm}$ disc) and the residual material rinsed with additional water $(2 \times 50 \mathrm{ml})$. Extracts were transferred to a tarred, round-bottomed flask and concentrated under va- 
cuum to a thick extract and dried at $60^{\circ} \mathrm{C}$.

\subsection{Preparation of Standard Solution}

Stock standard solution containing $1000 \mathrm{mg}$ per liter of iron was prepared by weighing $7.0217 \mathrm{~g}$ of ammonium ferrous sulphate. The weight of the metal salt was dissolved in a minimum of nitric acid, this was then transferred quantitatively to $1000 \mathrm{ml}$ volumetric flask and brought to volume with deionized water.

\subsection{Preparation of Standard Curve}

Series of standard solutions were prepared by suitable dilution of the stock solution in concentration that were expected in the sample solution. The instrumental setting was optimized for element to be measured (Table 1).

A calibration curve for the element was obtained by plotting the absorbance against the concentration of the standard solution. The curve was used to determine the concentration of the specific element in the sample solution. Figure 1 show the absorbance-concentration relationship and calibration curve for the element under investigation.

\subsection{Preparation of Plant Samples for Analysis}

Dried sample of aqueous, methanolic and acetone extracts, and powdered plant part of Acacia species and Mimosa (Acacia mearnsii) were used for the analysis.

5 grams of dried powdered plant parts and extracts were weighed accurately in a small beaker and covered with a glass watch. $37.5 \mathrm{ml}$ of nitric acid (conc.) were added and the mixture was allowed to stand at room temperature until initial reaction subsided, then heated on a sand bath until the production of brown $\mathrm{NO}_{2}$ fumes ceased. The solution was then cooled and $7.5 \mathrm{ml}$ of perchloric acid (60\%) were added and heating continued until almost half of the volume was evaporated. $10 \mathrm{ml}$ of sulphuric and nitric acids mixture (1:1) were added and heated until a clear colourless or pale yellow solution was obtained, then the solution was cooled and filtered into a $100 \mathrm{ml}$ volumetric flask, and completed to volume with deionized water. A blank solution was also prepared in the same way. The absorbance of the analyte in the sample solutions (Table 2) and the amount of the iron content was determined (Tables 3-6).

Table 1. Atomic Absorption Spectrophotometer (AAS) settings for the determination of Iron (Fe).

\begin{tabular}{ccccc}
\hline Element & Wavelength of spectral line $(\mathrm{nm})$ & Slit setting $(\mathrm{nm})$ & Light source & Flame type \\
\hline $\mathrm{Fe}$ & 248.3 & 0.2 & H.C.L. & A-Ac. \\
\hline
\end{tabular}

H.C.L. = Hollow-cathode Lamp, A-Ac. = Air-Acetylene.

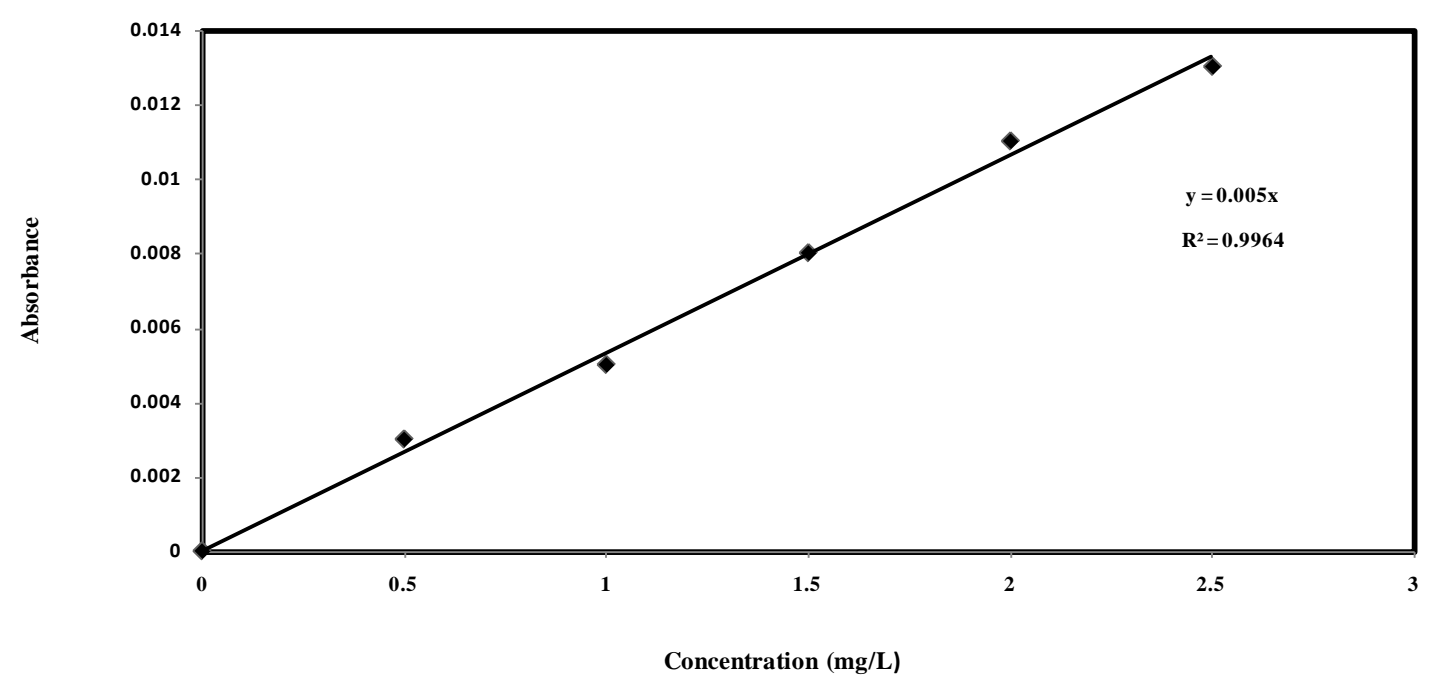

Figure 1. Absorbance of solutions of Iron (Fe) as a function of concentrations. 
Table 2. Absorbance of solutions of Acacia species bark extracts and mimosa (Acacia mearnsii) as determined by AAS (at $248.3 \mathrm{~nm})$.

\begin{tabular}{ccc}
\hline Species & Solvent of Extraction & Absorbance \\
\hline Acacia nilotica & Water & 0.009 \\
& $80 \%$ Methanol & 0.011 \\
& $70 \%$ Acetone & 0.012 \\
Acacia seyal & Water & 0.008 \\
& $80 \%$ Methanol & 0.008 \\
Acacia senegal & $70 \%$ Acetone & 0.008 \\
Mimosa (Acacia mearnsii) & Water & 0.010 \\
\hline
\end{tabular}

Table 3. Iron content of Acacia species bark extracts and samples as determined by AAS (at $248.3 \mathrm{~nm})$.

\begin{tabular}{|c|c|c|c|c|c|c|}
\hline \multirow[t]{2}{*}{ Species } & \multicolumn{3}{|c|}{ Fe concentration ${ }^{*}$ of Extracts (mg/L) } & \multicolumn{3}{|c|}{$\% \mathrm{Fe}$ in Extracts } \\
\hline & $\mathrm{H}_{2} \mathrm{O}$ & 80\% Methanol & $70 \%$ Acetone & $\mathrm{H}_{2} \mathrm{O}$ & 80\% Methanol & $70 \%$ Acetone \\
\hline A. nilotica & 0.00165 & 0.0020 & 0.00219 & 0.0033 & 0.0040 & 0.0044 \\
\hline A. seyal & 0.00146 & 0.00146 & 0.00146 & 0.0029 & 0.0029 & 0.0029 \\
\hline A.senegal & 0.00183 & 0.00145 & 0.00370 & 0.0037 & 0.0029 & 0.0040 \\
\hline \multirow[t]{2}{*}{ Species } & \multicolumn{6}{|c|}{ \% Fe Bark Samples } \\
\hline & \multicolumn{2}{|c|}{$\mathrm{H}_{2} \mathrm{O}$} & \multicolumn{2}{|c|}{ 80\% Methanol } & \multicolumn{2}{|c|}{ 70\% Acetone } \\
\hline A. nilotica & \multicolumn{2}{|c|}{0.00051} & \multicolumn{2}{|c|}{0.00102} & \multicolumn{2}{|c|}{0.00115} \\
\hline A. seyal & \multicolumn{2}{|c|}{0.00056} & \multicolumn{2}{|c|}{0.00075} & \multicolumn{2}{|c|}{0.00080} \\
\hline A. senegal & \multicolumn{2}{|c|}{0.00031} & \multicolumn{2}{|c|}{0.00032} & \multicolumn{2}{|c|}{0.00048} \\
\hline
\end{tabular}

*All concentrations are relative to standard solution of iron.

Table 4. Iron content of mimosa (Acacia mearnsii) as determined by AAS (at $248.3 \mathrm{~nm}$ ).

\begin{tabular}{cc}
\hline Species & \% Fe \\
\hline Mimosa (Acacia mearnsii) & 0.00475 \\
\hline
\end{tabular}

Table 5. Absorbances of solution of Acacia species bark, leaves, mature and immature fruits as determined by AAS (at $248.3 \mathrm{~nm})$.

\begin{tabular}{ccc}
\hline Species & Plant Part & Absorbance \\
Acacia nilotica & Leaves & 0.003 \\
Acacia seyal & Leaves & 0.002 \\
Acacia nilotica & Bark & Bark \\
Acacia seyal & Bark & 0.004 \\
Acacia senegal & Mature fruits & 0.002 \\
Acacia nilotica & Immature fruits & 0.001 \\
Acacia nilotica & 0.004 \\
\hline
\end{tabular}


Table 6. Iron content of Acacia species bark, leaves, mature and immature fruits as determined by AAS (at $248.3 \mathrm{~nm}$ ).

\begin{tabular}{ccc}
\hline Species & Plant part & \% Fe in plant part \\
\hline Acacia nilotica & Leaves & 0.1100 \\
Acacia seyal & Leaves & 0.0750 \\
Acacia nilotica & Bark & 0.1450 \\
Acacia seyal & Bark & 0.0750 \\
Acacia senegal & Bark & 0.0375 \\
Acacia nilotica & Mature fruits & 0.1450 \\
Acacia nilotica & Immature fruits & 0.1100 \\
\hline
\end{tabular}

\section{Results and Discussion}

The solubility and isolation of organic compounds by solvent extraction have traditionally been made with the determinant in uncharged form, but this method is sufficient when the compound is highly hydrophilic. However, organic compounds that can appear in ionized form, can be extracted as ion-pairs. In this study, the amount of iron content of the sample and the extracts of Acacia species was determined. Iron content was determined by wet digestion method and using atomic absorption spectrophotometer, because wet digestion method was more reproducible than the dry ashed method. Also comparison of the amount of iron content present in the plant part materials of Acacia species was made with the extract of different solvents of the same species, and finally comparison was also made with the iron content present in the Mimosa (Acacia mearnsii) extract.

The iron content present in leaves, bark, mature and immature fruits of Acacia nilotica was determined. Bark and mature fruits of Acacia nilotica had the highest and equal percentage of iron content $(0.1450 \%)$, while leaves and immature fruits of the same species had intermediate values and equal percentage $(0.1100 \%)$. The percentage of iron content of leaves and bark of Acacia seyal had equal percentage $(0.0750 \%)$, while the bark of Acacia senegal has much lower percentage (0.0375\%), (Table 6). All results concerned the determination of iron content in this study have been expressed in terms of iron concentration (Figure 1), suggest that this technique may underestimate the quantity of iron content present.

Iron content present in Acacia species was affected by different solvent extraction. Iron content in the extracts was determined by the same analytical methods. The iron content of bark extracts of Acacia nilotica and Acacia senegal had highest percentage $(0.0044 \%$ and $0.0040 \%$ respectively) and that of Acacia seyal has much lower percentage $(0.0029 \%)$ (Table 3$)$. In contrast, the iron content of bark extract of the three species of Acacia had lower percentage compared to that of Mimosa (Acacia mearnsii) (0.00475\%) (Table 4). The effect of solvents on the extraction of iron from the sample of Acacia species can be explained by two reasons. One of the important reason is that the hydrogen bonding properties between aqueous acetone, for example, and tannins are stronger than present between iron and aqueous acetone, since iron and tannins are co-occurring in the same sample, and not on the structure of tannins (or could be extracted completely in this case). The other reason is that tannins have anionic properties, while the iron has cationic properties, since the extraction occurred as ionpairs i.e. anionic plus cationic. We can conclude that extraction by aqueous acetone produce higher percentage of tannins and lower percentage of iron content, and this makes it useful for the extraction processes, when compared with Mimosa (Acacia mearnsii) tannins.

\section{Conclusions}

We can conclude that among the three Acacia species studied, Acacia nilotica is the richest in tannins content, and within the Acacia nilotica parts, mature and immature fruits were the highest in iron content, while the barks of the three Acacia species was the least. Also we can conclude that the extraction by aqueous acetone produce lower percentage of iron content, and this makes it useful for the extraction processes, when compared with Mimosa (Acacia mearnsii) tannins.

Recommendations that could be drawn from this study are that additional studies will be necessary to estimate variation iron content within and among population of each species. 


\section{Acknowledgements}

Special thanks to the Department of Chemistry, University of Khartoum where this evaluation and investigation have been carried out, for laboratory facilities and valuable assistance in the use of various equipments. Thanks are extended to the National Centre for Leather Technology, Khartoum Tannery and White Nile Tannery for continuous help during the course of the study.

\section{References}

[1] Evans, U.R. (1972) The Rusting of Iron: Causes and Control, Studies in Chemistry. No. 7, Edward Arnol, London.

[2] Mayne, J.E.O. (1953) The Oxidation of Ferrous Hydroxide. Journal of the Chemical Society, 129-132. http://dx.doi.org/10.1039/jr9530000129

[3] Schwertmann, U. and Fechter, H. (1994) The Formation of Green Rust and Its Transformation to Lepidocrocite. Clay Minerals, 29, 87-92. http://dx.doi.org/10.1180/claymin.1994.029.1.10

[4] Sharma, S.K. (2012) Green Corrosion Chemistry and Engineering: Opportunities and Challenges. Wiley-VCH Verlag GmbH and Co. KGaA, 1.

[5] Loyaux-Lawniczak, S., Refait, Ph., Lecomte, P., Ehrhardt, J.-J. and Genin, J.-M.R. (1999) The Reduction of Chromate Ions by Fe(II) Layered Hydroxides. Hydrology and Earth System Sciences, 3, 593-599. http://dx.doi.org/10.5194/hess-3-593-1999

[6] Kanagy, J.R. (1938) Influence of Copper and Iron Salts on the Behavior of Leather in the Oxygen Bomb. Journal of Research of the National Bureau of Standards, 20, 849-857. http://dx.doi.org/10.6028/jres.020.008

[7] Landrot, G., Tappero, R., Webb, S.M. and Sparks, D.L. (2012) Arsenic and Chromium Speciation in an Urban Contaminated Soil. Chemosphere, 88, 1196-1201. http://dx.doi.org/10.1016/j.chemosphere.2012.03.069 